\title{
Histochemical Test of root, petiole and leaf of Kelembak (Rheum officinale Baill.)
}

\author{
Nurhasanah \& Dyah Iriani* \\ Department of Biology, Faculty Math and Natural Resources Science, Universitas Riau, Indonesia
}

\author{
Article History \\ Received : August $04^{\text {th }}, 2021$ \\ Revised : August $28^{\text {th }}, 2021$ \\ Accepted : September $06^{\text {th }}, 2021$ \\ Published : September $16^{\text {th }}, 2021$ \\ *Corresponding Author: \\ Dyah Iriani, \\ Department of Biology, Faculty \\ Math and Natural Resources \\ Science, Universitas Riau, \\ Indonesia \\ Email: \\ dyah.iriani@lecturer.unri.ac.id
}

\begin{abstract}
Kelembak (Rheum officinale Baill.) is perennial shrub with pharmacological activities, and well-known as one of traditional herbal medicine used widely in the world. The phytochemical study, as well as histochemical test, is pivotal to determine the potency of herbs used for disease treatment. Based on its secondary metabolite content. Histochemical test of R.officinale vegetative organs had not been reported. This study aims to determine the content of compounds in the vegetative organs of kelembak and provide information on the anatomical position of each compound in root, petiole and leaf. The preparation of histochemical test used freehand section method. Each sample was made in three replications for this test. A total of four secondary metabolites were examined in this study, i.e. alkaloid, tannin, lipid and flavonoid. The positive content of each compound was indicated by the coloration change. The specimens were then observed and photographed using light microscope. The results showed that the root, petiole and leaf showed positive content of alkaloids, tannins, lipids and flavonoids. However, the anatomical position of each secondary metabolites are different among root, petiole and leaf. The results of this study provide the first information of histochemistry vegetative organs of Rheum officinale.
\end{abstract}

Keywords: Histochemistry, medicinal plants, Polygonaceae, Rheum officinale Baill.

\section{Pendahuluan}

Famili Polygonaceae terdiri 59 genus dan 5.385 spesies dimana 1.384 nama spesies yang diterima (The Plant List 2013). Rheum officinale Baill.merupakan spesies dari genus Rheum suku Rumiceae (Sanchez et al. 2011). Kelembak (Rheum officinale Baill.) dikenal dengan sebutan Rhubarb. Tanaman ini merupakan semak tahunan dengan pertumbuhan tanaman 25-80 cm. Kelembak memiliki karakter akar tunggang, lunak, bulat berwarna coklat. Batang berwarna coklat pendek beralur melintang.Daun tunggal, bertangkai dengan helaian daun berbentuk bulat telur. Perbungaan majemuk, berkelamin 2 atau 1. Buah berbentuk seperti padi, bulat telur berwarna merah (Adriyanti 2014).

Rhubarb merupakan obat tradisional Cina, memiliki banyak farmakologis, seperti pencahar, anti-inflamasi, antibakteri, anti-terapatik dan anti- kanker (Xiao et al. 1984; Tseng et al. 2006; Li et al. 2009). Pemanfaatan yang dilakukan pada genus Rheum, misal pada organ akar dimanfaatkan untuk gangguan pencernaan serta masalah haid. Penggunaannya dengan cara akar ditumbuk kemudian direbus (Rokaya et al. 2010). Selain itu digunakan untuk pengobatan patah tulang dengan cara menumbuk akar sampai halus hingga menjadi bentukan pasta, kemudian diolesi pada bagian yang sakit (Shrestha \& Shivcharn 2003). Di Indonesia kelembak banyak digunakan masyarakat lokal sebagai obat tradisional untuk campuran jamu serta ramuan parem (Widyastuti et al. 2014). Masyarakat menengah ke bawah di Yogyakarta dan Jawa Tengah menggunakan tanaman ini sebagai bahan campuran rokok atau disebut "klembak menyan" (Departemen Kesehatan RI 2010).

Organ vegetatif tanaman kelembak seperti akar, batang dan daun memiliki sejumlah 
kandungan senyawa. Kandungan senyawa di akar kelembak berupa senyawa turunan antrakuinon seperti rhein, emodin dan chrysophanol (Zhao et al. 2014). Batang mengandung senyawa rhein, emodin dan asam krisofanat. Kandungan senyawa pada daun kelembak berupa antraglikosida dan frangulaemodin yang memiliki sifat purgatif (pencahar) cukup tinggi dan kandungan flavonoid yang terdapat di dalamnya (Departemen Kesehatan RI 2010).

Penggunaan tanaman obat tidak luput dari
adanya pengontrolan kualitas guna mempertimbangkan suatu tanaman dapat dijadikan obat herbal dan memastikan nilai mutu tanaman (Martins \& Gloria 2006). Pengujian histokimia dilakukan untuk mengetahui lokasi suatu senyawa metabolit yang disekresikan tanaman secara mikroskopis (Kolb \& Muller 2004).

Beberapa penelitian dari genus Rheum sudah dilakukan. Penelitian ini mencakup senyawa bioaktif Rheum (Püssa et al. 2009; Gao et al. 2013; Malik et al. 2018; Ghorbani et al. 2019; Khattak et al. 2020). Studi histokimia umumnya dilakukan pada genus Polygonum, namun untuk genus Rheum khususnya Rheum officinale belum pernah dilaporkan. Penelitian ini dilakukan untuk mengetahui senyawa alkaloid, tanin, lipid dan flavonoid yang terkandung di organ akar, petiol dan daun kelembak. Hasil penelitian ini memberikan informasi mengenai konstituen seluler dan lokasi kandungan senyawa metabolit melalui uji histokimia. Selain itu juga sebagai informasi bahan baku obat herbal tanaman tersebut.

\section{Bahan dan Metode}

\section{Bahan dan alat}

Bahan yang digunakan adalah tanaman kelembak berumur 1-1.5 tahun diperoleh dari B2P2TOOT (Balai Besar Penelitian dan Pengembangan Tanaman Obat dan Obat Tradisional) Tawangmangu, Jawa Tengah. Bahan uji histokimia menggunakan reagen Wagner, Sudan IV $0,03 \%$, larutan feri triklorida $10 \%$, Natrium karbonat dan $\mathrm{NaOH} 10 \%$. Pembuatan sayatan histokimia menggunakan free hand section. Pengamatan dilakukan menggunakan mikroskop cahaya Olympus CX23 yang dilengkapi dengan kamera optilab.

\section{Tahapan Penelitian}

\section{Uji alkaloid}

Sayatan melintang organ ditetesi reagen Wagner dengan komposisi 1,27 gr Iodin dan 2 gr Kalium iodide yang dilarutkan dalam $100 \mathrm{ml}$ akuades, kemudian ditunggu selama 5 menit. Hasil positif dinyatakan jika pada gambaran sel berwarna coklat kemerahan (Furr \& Mahlberg 1981).

\section{Uji Tanin}

Sayatan melintang organ tanaman kelembak ditetesi oleh campuran $\mathrm{FeCl}_{3} 10 \%$ dan Natrium karbonat. Positif tanin ditunjukkan dengan sel-sel terwarnai menjadi hijau gelap sampai hitam (Johansen 1940).

\section{Uji Lipid}

Sayatan melintang organ tanaman kelembak di tetesi alkohol $70 \%$ selama 1 menit, selanjutnya dipanaskan dengan Sudan IV 0,03\% di waterbath $40^{\circ} \mathrm{C}$ selama 30 menit. Sampel dicuci dengan alkohol $70 \%$ dan jika sel-sel tampak berwarna merah-kuning-jingga menandakan positif adanya lipid (Boix et al. 2011).

\section{Uji Flavonoid}

Sayatan melintang organ tanaman kelembak ditetesi dengan larutan $\mathrm{NaOH} 10 \%$. Hasil positif dari kandungan senyawa flavonoid ditandai dengan gambaran sel berwarna merah (Mulyani \& Toga 2011).

\section{Hasil dan Pembahasan}

Struktur seluler dari setiap bagian tanaman menghasilkan senyawa metabolit yang keberadaannya pada jaringan tumbuhan mampu dideteksi melalui uji histokimia. Reaksi dari reagen tertentu pada uji histokimia menghasilkan warna spesifik. Hasil uji histokimia pada akar, daun dan petiole kelembak menunjukkan positif adanya senyawa metabolit pada jaringan di setiap organ. Tabel 1. Indikasi positif adanya akumulasi senyawa alkaloid ditandai dengan sel maupun jaringan terwarnai coklat kemerahan, sedangkan tanin ditandai dengan warna hitam hingga hijau, kemudian lipid ditandai dengan warna merah, kuning hingga jingga serta positif flavonoid ditandai dengan warna merah. Berikut ini hasil uji histokimia tanaman kelembak. 
Tabel 1. Hasil uji histokimia pada organ vegetatif tanaman kelembak

\begin{tabular}{|c|l|c|c|c|c|}
\hline \multicolumn{2}{|c|}{$\begin{array}{l}\text { Bagian } \\
\text { Tanaman }\end{array}$} & \multicolumn{4}{c|}{ Uji Histokimia } \\
\cline { 2 - 6 } Akar & Alkaloid & Tanin & Lipid & Flavonoid \\
\cline { 2 - 6 } & Keloderm & - & + & + & - \\
\cline { 2 - 6 } & $\begin{array}{l}\text { Jari-jari } \\
\text { xilem/ } \\
\text { floem }\end{array}$ & - & + & - & + \\
\cline { 2 - 6 } & Xilem & - & - & + & - \\
\cline { 2 - 6 } & Idioblas & + & - & - & - \\
\hline Daun & Trikoma & + & - & + & - \\
\cline { 2 - 6 } & Epidermis & - & - & + & - \\
\cline { 2 - 6 } & Palisade & - & - & - & + \\
\cline { 2 - 6 } & $\begin{array}{l}\text { Bunga } \\
\text { karang }\end{array}$ & + & - & - & + \\
\cline { 2 - 6 } & $\begin{array}{l}\text { Berkas } \\
\text { pembuluh }\end{array}$ & - & + & - & - \\
\hline Petiol & Epidermis & + & + & + & - \\
\cline { 2 - 6 } & Korteks & - & - & - & + \\
\cline { 2 - 6 } & Xilem & + & + & - & - \\
\cline { 2 - 6 } & Floem & + & - & + & - \\
\cline { 2 - 6 } & Idioblas & - & - & + & - \\
\hline
\end{tabular}

Keterangan :

$(+)=$ terdapat metabolit sekunder

$(-)$ = tidak terdapat metabolit sekunder

\section{Histokimia Akar}

Hasil uji histokimia pada akar menujukkan keberadaan senyawa alkaloid, tanin, lipid dan flavonoid yang terlokalisasi pada setiap jaringan. Keberadaan senyawa alkaloid terdeteksi di idioblas (Gambar 1.B). Hal ini di dukung oleh Nugroho (2014) yang menyatakan bahwa alkaloid banyak ditemukan di sel mesofil dan idioblas. Umumnya alkaloid sering dijumpai pada organ akar, namun juga ditemukan pada organ batang dan rizoma. Menurut Rohyani et al. (2015), peranan senyawa alkaloid dalam bidang kesehatan antara lain: mengurangi rasa sakit, antimikroba, obat penenang, dan obat penyakit jantung.

Keberadaan tanin ditemukan di jaringan gabus, jari-jari xilem, jari-jari floem dan feloderm (Gambar 1.C). Kemper (1999) menyatakan pada akar kelembak komponen tanin sebesar 5\%-10\%. Mulyani \& Toga (2011), keberadaan tanin tidak dijumpai pada organ akar maupun rimpang melainkan pada bagian seperti jaringan periderm, jaringan pembuluh, buah yang belum masak, kulit biji, dan jaringan yang tumbuh karena adanya penyakit. Uji lipid terdeteksi positif di jaringan gabus dan xilem (Gambar 1.D).Oliveira et al. (2015) melakukan uji histokimia pada akar Vernonia ferruginea Less. (Asteraceae) positif lipid pada endoderm. Uji flavonoid positif di korteks, jari-jari xilem dan jari-jari floem (Gambar 1.E). Matias et al. (2016), kehadiran flavonoid ditemukan di feloderm korteks S.agrarium, S.lycocarpum, S.palinacanthum, S.paniculatum dan S.stipulaceu, kecuali floem yang hanya dijumpai pada S.lycocarpum (Solanaceae).

Berdasarkan uji fitokimia dan bioaktif spesies Rheum yang dilakukan Singh et al. (2016) khususnya akar menemukan sejumlah senyawa antrakuinon, asam fenolik, flavonoid dan tanin. Sehingga hal ini juga didukung oleh hasil uji histokimia yang dilakukan pada akar kelembak memang positif tanin dan flavonoid. 

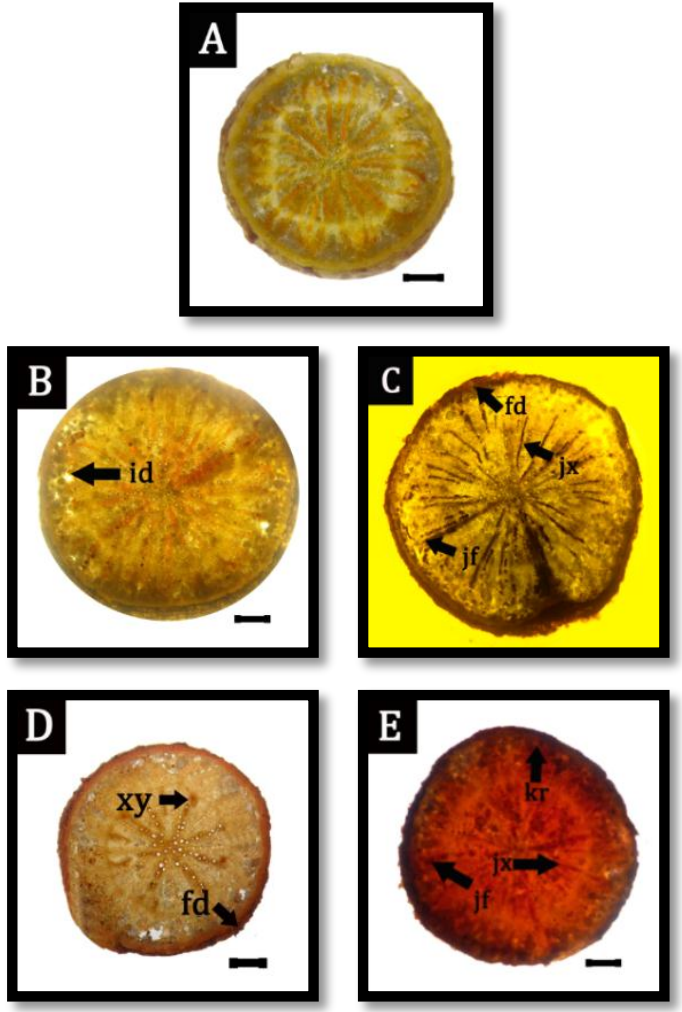

Gambar 1. Penampang melintang uji histokimia akar kelembak : $\mathrm{A}=$ Sebelum pewarnaan, $\mathrm{B}=\mathrm{Uji}$ alkaloid, $\mathrm{C}=\mathrm{Uji}$ tanin, $\mathrm{D}=$ Uji lipid $\mathrm{E}=$ Uji flavonoid Keterangan: $\mathrm{fd}=$ Feloderm, $\mathrm{kr}=$ Korteks, jf = Jari-jari floem, jx = Jarijari xilem, $\mathrm{xy}=$ Xilem, $\mathrm{id}=$ Idioblas Skala $300 \mu \mathrm{m}$

\section{Histokimia Petiol}

Jaringan alami sebelum pemberian reagen uji histokimia berwarna merah di bagian terluar, sementara itu bagian dalam berwarna hijau kekuningan. Hasil potongan melintang di beberapa bagian sudah terlihat tipis (Gambar 2.A). Uji alkaloid ditandai dengan warna coklat kemerahan pada bagian jaringan. Reaksi dari reagen Wagner akan mengendapkan protoplas (Furr \& Mahlberg 1981). Kehadiran senyawa alkaloid terdeteksi di bagian epidermis, xilem dan floem (Gambar 2.B). Berbeda dengan Teixeira et al. (2016), alkaloid terdeteksi di bagian parenkim kortikol dan medular pada Cordiera sessilis (Vell.) Kuntze (Rubiaceae).
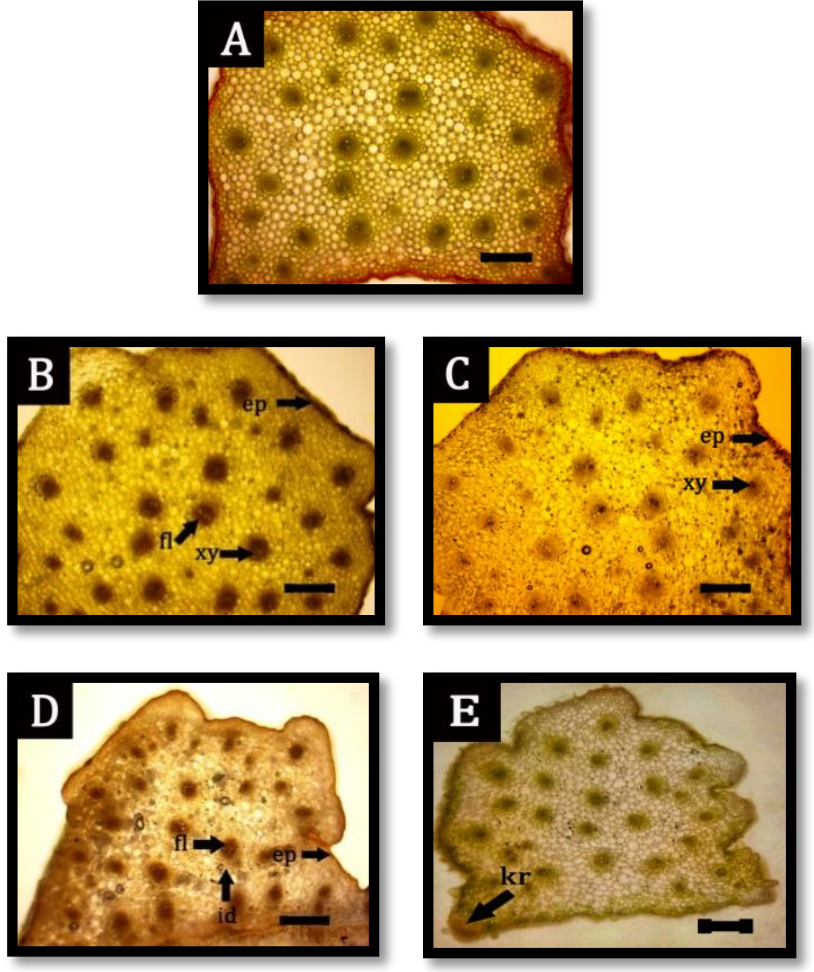

Gambar 2. Penampang melintang uji histokimia petiol kelembak: $\mathrm{A}=$ Sebelum pewarnaan, $\mathrm{B}=\mathrm{Uji}$ alkaloid, $\mathrm{C}=\mathrm{Uji}$ tanin, $\mathrm{D}=$ Uji lipid, $\mathrm{E}=$ Uji flavonoid. Keterangan: $\mathrm{ep}=$ Epidermis, $\mathrm{kr}=$ Korteks, $\mathrm{fl}=$ Floem, $\mathrm{xi}=$ Xilem, $\mathrm{id}=$ idioblas. Skala $300 \mu \mathrm{m}$.

Positif tanin di bagian epidermis dan xilem (Gambar 2.C). Namun, pada Caesalpinia spinosa (Fabaceae) terdapat kandungan senyawa polifenol pada bagian sel parenkim (Martel et al. 2016). Uji lipid positif dijumpai pada bagian epidermis, floem dan idioblas (Gambar 2.D). Hal serupa juga dijumpai pada Dipteryx odorata dan Taralea oppositifolia (Fabaceae) oleh Silva et al. (2019) positif lipid di idioblas. Selain itu, Andradea (2017) pada petiole Sapium glandulosum (Euphorbiaceae) ditemukan lipid di bagian epidermis. Keberadaan flavonoid dijumpai pada parenkim korteks (Gambar 2.E). Berbeda dengan Aprilia (2016), menemukan senyawa flavonoid di trikoma pada Coleus scutellarioides (Lamiaceae). 


\section{Histokimia Daun}

Hasil potongan melintang sebelum pemberian reagen uji histokimia menunjukkan jaringan yang berwarna abu muda, sementara ada beberapa jaringan berwarna hijau muda. Hal ini dikarenakan potongan yang dibuat masih terlalu tebal (Gambar 3.A).
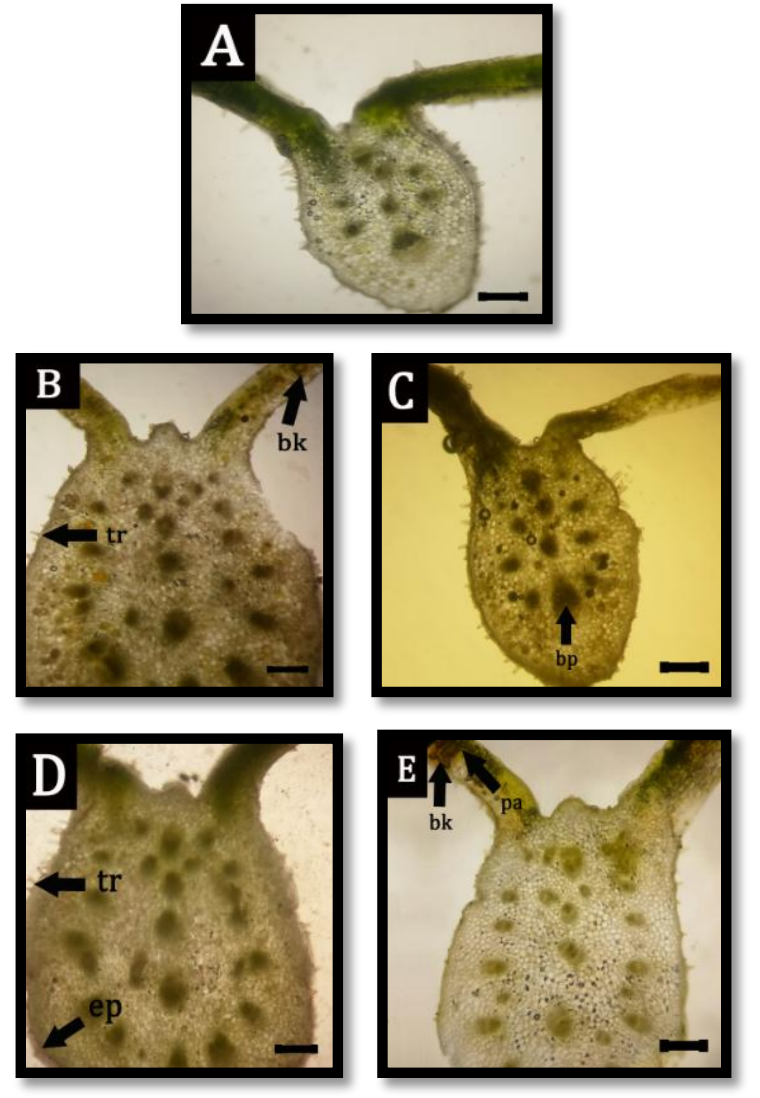

Gambar 3. Penampang melintang uji histokimia daun kelembak: $\mathrm{A}=$ Sebelum pewarnaan, $\mathrm{B}=\mathrm{Uji}$ alkaloid, $\mathrm{C}=\mathrm{Uji}$ tanin, D = Uji lipid, E = Uji Flavonoid Keterangan: $\operatorname{tr}=$ Trikoma, ep $=$ Epidermis, $\mathrm{pl}=$ Palisade, $\mathrm{bk}=$ Bunga karang, $b p=$ Berkas pembuluh. Skala $300 \mu \mathrm{m}$

Kandungan senyawa alkaloid terdeteksi positif di trikoma dan parenkim bunga karang (Gambar 3.B). Afifah (2018) menemukan keberadaan senyawa alkaloid pada trikoma daun Pohpohan (Pilea trinervia W.). Hal yang sama juga ditemukan Aprilia (2016), pada uji histokimia daun Jawer Kotok (Coleus scutellarioides) positif alkaloid pada struktur sekretori berupa trikoma.
Khatoon (2017) pada Coelogyne cristata positif alkaloid pada bagian epidermis dan mesofil bunga karang.

Keberadaan senyawa tanin ditemukan di berkas pembuluh melalui ibu tulang daun (Gambar 3.C). Sementara itu, Lopes et al. (2009) melakukan uji histokimia ditemukan senyawa fenolik pada parenkim palisade dan bunga karang. Namun berbeda dengan Rafaela et al. (2019), keberadaan tanin dijumpai pada epidermis $A$. altilis dan idioblas, parenkim palisade dan bunga karang $A$. Heterophyllus (Moraceae).

Trikoma dan epidermis positif terdeteksi lipid (Gambar 3.D). Rafaela et al. (2019), mengungkapkan positif lipid pada kutikula,epidermis dan kolenkim dari A. altilis dan A. heterophyllus pada kutikula, idioblas, parenkim bunga karang dan berkas pembuluh. Selain itu, Lopes et al. (2009) menemukan adanya lipid di kutikula dan kelenjar sekretori pada Polygonum hydropiperodes Michaux (Polygonaceae).

Flavonoid merupakan salah satu senyawa metabolit dari golongan fenol. Flavonoid memiliki kemampuan dalam penangkapan radikal bebas serta penghambat oksidasi lipid (Banjarnahor \& Artanti 2014; Treml \& Smejkal 2016). Positif flavonoid dijumpai pada bagian mesofil yaitu palisade dan bunga karang (Gambar 3.E). Penelitian Andradea et al. (2017), uji histokimia Sapium glandulosum (Euphorbiaceae) menemukan adanya senyawa fenol di mesofil. Lopes et al. (2009) mendeteksi positif adanya kandungan flavonoid pada kelenjar sekretori Polygonum hydropiperodes Michaux (Polygonaceae).

\section{Kesimpulan}

Hasil uji histokimia menunjukkan hasil positif kandungan senyawa alkaloid, tanin, lipid dan flavonoid pada organ akar, petiol dan daun. Namun keberadaan kandungan senyawa menunjukan perbedaan posisi secara anatomi pada ketiga organ tersebut.

\section{Ucapan Terima kasih}

Penulis mengucapkan terima kasih kepada Program Hibah Penelitian Mahasiswa dari Asian Devolopment Bank (ADB) Tahun Anggaran 2020 dengan Nomor DIPA-023.17.2.677564/2020. 


\section{Referensi}

Adriyanti DR. (2014). Buku Acuan Umum Tumbuhan Obat Indonesia Jilid III. Jakarta: Dian Rakyat.

Afifah N. (2018). Analisis Anatomi, Struktur Sekretori, Dan Histokimia Tanaman Pohpohan (Pilea trinervia W.) [Skripsi]. Bogor: Institut Pertanian Bogor.

Andrade EA, Daniela GF, Livia ECL, Katia SP, Paulo VF \& Jane MB. (2017). Anatomy and Histochemistry of Leaves and Stems of Sapium glandulosum. Brazilian Journal of Pharmacognosy. $\quad 27(3)$ : 1-8. http://dx.doi.org/10.1016/j.bjp.2017.01.001

Aprilia A. (2016). Analisis Sebaran, Pertumbuhan, Perkembangan, Dan Histokimia Struktur Sekretori Pada Tumbuhan Jawer Kotok (Coleus scutellarioides). [Skripsi]. Bogor: Institut Pertanian Bogor.

Banjarnahor S \& Artanti N. (2014). Antioxidant properties of flavonoids. Medical Journal of Indonesia. 23 (4): $239-244$. https://doi.org/10.13181/mji.v23i4.1015

Boix YF, Rossi A, Christian EPV \& Alice S. (2011). Glandular Trichomes of Rosmarinus officinalis L.: Anatomical and Phytochemical Analyses of Leaf Volatiles. Plant Biosystem. 1-9. http://dx.doi.org/10.1080/11263504.2011.5 84075

Departemen Kesehatan RI (2010). Suplemen I Farmakope Herbal Indonesia. Jakarta: Departemen Kesehatan RI.

Furr M \& Paul GM. (1981). Histochemical Analyses of Laticifers and Glandular Trichomes in Cannabis sativa. Journal of Natural Products. 44 (2): 153-159. http://dx.doi.org/10.1021/np50014a002

Gao L, Xudong X \& Junshan Y. (2013). Chemical Constituents of The Roots OfRheum officinale. Chemistry of Natural Compounds. 49 (4): 603-605. http://dx.doi.org/10.1007/s10600-013-06897

Ghorbani A, Mohammad SA \& Azar H. (2019). Pharmacological properties of Rheum turkestanicum Janisch. Heliyon. 5(6): 1-8. https://doi.org/10.1016/j.heliyon.2019.e019 86

Johansen DA. (1940). Plant Microtechnique. New York dan London: McGraw-Hill Book Company Inc.

Kemper KJ. (1999). Longwood Herbal Task Force: Rhubarb root (Rheum officinale or Rheumpalmatum). http://www.mcp.edu/herbal/default.htm. [20 Januari 2019]

Khatoon S. (2017). A Novel Histological Approach for Identification of Alkaloid Bearing Plants. Internastion Journal of Botany.13 (1): 2836. http://dx.doi.org/10.3923/ijb.2017.28.36

Khattak AK, Syeda MH \& Shahzad SM. (2020). General Overview of Phytochemistry and Pharmacological Potential of Rheum Palmatum (Chinese Rhubarb). Innovare Journal of Ayurvedic Sciences. 8(6): 1-5. http://dx.doi.org/10.22159/ijas.2020.v8i6.3 9192

Kolb D \& Müller M. (2004). Light, Conventional and Environmental Scanning Electron Microscopy of the Trichomes of Cucurbita pepo subsp. pepo var. styriaca and Histochemistry of Glandular Secretory Products. Ann Bot. 94: 515-526. http://dx.doi.org/10.1093/aob/mch180

Li WY, Chan SW, Guo DJ, Chung MK, Leung TY \& Yu PH. (2009). Water Extract of Rheum officinale Baill. Induces Apoptosis in Human Lung adenocarcinoma A549 and Human Breast Cancer MCF-7 cell lines.J.Ethnopharmacol. 124(2): 251-256. http://dx.doi.org/10.1016/j.jep.2009.04.030

Lopes DES, Virgínia DCO, João FM, Alaíde BDO \& Rose LRPJ. (2009). Anatomical and Histochemical Characters of Polygonum 
hydropiperodes Michaux, Polygonaceae. Brazilian Journal of Pharmacognosy. 19(3): 677-685. http://dx.doi.org/10.1590/S0102695X2009000500005

Malik MA, Showkat AB, Muneeb UR, Showket S, Zubair AA, Purnima S \& Sheikh BA. (2018). Phytochemical analysis and antimicrobial activity of Rheum emodi(Rhubarb) rhizomes. The Pharma Innovation Journal. 7(5):17-20. Corpus ID: 96437558

Martel C, Nancy R, Manuel M, Rosa A, Elizabeth N \& Julio S. (2014). Caesalpinia spinosa (Caesalpiniaceae) Leave: Anatomy, Histochemistry and Secondary Metabolite. Brazilian Journal of Botany.http://dx.doi.org/10.1007/s40415014-0059-0

Martins, AR \& Gloria BA Da (2006). Morphoanatomy of Vegetative Organs Smilax polyanthav Griseb. Brazillian Journal of Botany.29 (4): 555-567. https://doi.org/10.1590/S010084042006000400005

Matias LJ, Mercadante MO, Royo VA, Ribeiro LM, Santos AC \& Fonseca JMS. (2016). Structure and histochemistry of medicinal species of Solanum. Revista Brasileira de Farmacognosia. $26 \quad$ (2): 147-160. http://dx.doi.org/10.1016/j.bjp.2015.11.00 02

Mulyani S \& Toga L. (2011). Analisis flavonoid dan tannin dengan metoda mikroskopimikrokimiawi. Majalah Obat Tradisional. 16 (3): 109-114.

Nugroho LH. (2014). Peran Anatomi dalam Studi Biosintesis dan Akumulasi Metabolit Sekunder pada Tumbuhan. Naskah Pidato Pengukuhan Guru Besar Universitas Gadjah Mada.Yogyakarta.

Oliveira RC de1, Vasconcelos FSC, Bastos AVS, Vasconcelos JM \& Rodrigues AA. (2015). Anatomical and histochemical analysis of vegetative organs of Vernonia ferruginea
Less. (Asteraceae). African Journal of Biotechnology. 14 (38): 2734-273. http://dx.doi.org/10.5897/AJB2015.14934

Püssa T, Piret R, Kristina K \& Ain R. (2010). Polyphenolic Composition of Roots and Petioles of Rheum rhaponticum L. Phytochemical Analysis. 20 (2): 98-103. http://dx.doi.org/10.1002/pca.1102

Rafaela DS, Marília BC, Rafael JRP, Luiz CA \& Karina PR. (2019). Comparative anatomy and histochemistry of the leaf blade of two species of Artocarpus. Anais da Academia Brasileira de Ciências. 91(1): 1-10. http://dx.doi.org/10.1590/0001-

3765201820170922

Rohyani IM, Aryanti E, \& Suripto. (2015). Kandungan fitokimia beberapa jenis tumbuhan lokal yang sering dimanfaatkan sebagai bahan baku obat di Pulau Lombok. Prosiding Seminar Nasional Masyarakat Biodiversitas Indonesia. 1(2): 388-391.

Rokaya MB, Zuzana M \& Binu T. (2010). Ethnobotanical Study of Medicinal Plants from the Humla District of Western Nepal. Journal of Ethnopharmacology. 130 (3): 485-504.

https://doi.org/10.1016/j.jep.2010.05.036

Sanchez A, Tanja MS, Janelle MB \& Kathleen AK. (2011). Taxonomy of Polygonoideae (Polygonaceae): A new tribal classification. Journal TAXON. 60 (1): 151-160. https://doi.org/10.1002/tax.601013

Shrestha PM \& Shivcharn SD. (2003). Medicinal Plant Diversity and Use in the Highlands of Dolakha District, Nepal Journal of Ethnopharmacology. $\quad 86(1)$ : $\quad 81-96$. https://doi.org/10.1016/S0378-8741 (03)00051-5

Silva PMF, Eduardo OS, Marleide de SCR, Laísa MR de Castrod \& Inácio SS. (2019). Anatomical dan Histochememical Characterization of Dipteryx odorata and Taralea oppositifolia, Two Native Amazonian Species. Revista Brasileira de 
Farmacognosia. 29: 425-433. https://doi.org/10.1016/j.bjp.2019.05.004

Singh P, Geeta JPant \& MSM Rawat. (2016). Phytochemistry and Biological Activity Perspectives of Rheum Species. The Natural Products Journal. 6: 84-93. https://doi.org/10 $.2174 / 2210315506666151208212726$

Teixeira TR, Marlúcia SP \& Ana HFC. (2016). Leaf anatomy of Cordiera sessilis (Vell.) Kuntze (Rubiaceae). Acta Scientiarum Biological Science. 38(3): 355-364. http://dx.doi.org/10.4025/actascibiolsci.v38 i3.29902

The Plant List. (2013). Version 1.1. http://www.theplantlist.org/ (Diakses 19 Oktober 2020).

Treml J \& Smejkal K. (2016). Flavonoids as potent scavengers of hydroxyl radicals.Comprehensive Reviews in Food Science and Food Safety. 15: 720-738. https://doi.org/10.1111/1541-4337.12204

Tseng SH, Lee HH, Chen LG, Wu CH \& Wang, CC. (2006). Effects of Three Purgative Decoctions on Inflammatory Mediators. $J$. Ethnopharmacol. 105(1): 118-124. doi.org/10.1016/j.jep.2005.10.003

Widyastuti SH, Mulyani H \& Ekowati VI. (2014). Fitotherapy dalam Manuskrip-Manuskrip Jawa. Laporan Penelitian LPPM UNY.

Xiao P, He L \& Wang L. (1984). Ethnopharmacologic Study of Chinese Rhubarb. J. Ethnopharmacol. 10(3): 275293. https://doi.org/10.1016/0378-8741 (84)90016-3

Zhao N, Zhang X \& HU Chang J. (2014). Metabolomics analysis revealing multiple compounds changed in rhubarb after processing. China Journal of Chinese Materia Medica. 39(9): 1607-1613. http://dx.doi.org/10.4268/cjcmm20140913 